\title{
CSF lactate for accurate diagnosis of community-acquired bacterial meningitis
}

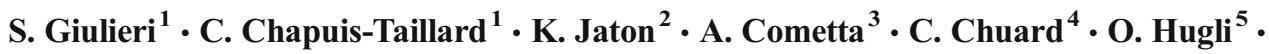 \\ R. Du Pasquier ${ }^{6} \cdot$ J. Bille $^{1,2} \cdot$ P. Meylan ${ }^{1,2} \cdot{\text { O. } \text { Manuel }^{1} \cdot \text { O. Marchetti }}^{1}$
}

Received: 3 April 2015 / Accepted: 2 July 2015 / Published online: 19 August 2015

(C) Springer-Verlag Berlin Heidelberg 2015

\begin{abstract}
CSF lactate measurement is recommended when nosocomial meningitis is suspected, but its value in community-acquired bacterial meningitis is controversial. We evaluated the diagnostic performance of lactate and other CSF parameters in a prospective cohort of adult patients with acute meningitis. Diagnostic accuracy of lactate and other CSF parameters in patients with microbiologically documented episodes was assessed by receiver operating characteristic (ROC) curves. The cut-offs with the best diagnostic performance were determined. Forty-five of 61 patients $(74 \%)$ had a
\end{abstract}

This study received the ICAAC Program Committee Award in Clinical Microbiology and Diagnosis at the 52nd ICAAC, San Francisco, CA, USA, September 9-12, 2012 (Oral presentation 1321 - \# L1-1221, session "New Insights in Bacterial Meningitis") and was presented at the Annual Meeting of the Swiss Societies for Infectious Diseases, Hospital Hygiene, and Travel Medicine, Lugano, May 30, 2013 (Oral presentation).

O. Manuel and O. Marchetti contributed equally to this work.

S. Giulieri

Stefano.Giulieri@chuv.ch

1 Infectious Diseases Service, Department of Medicine, Lausanne University Hospital (CHUV), Rue du Bugnon 46, 1011 Lausanne, Switzerland

2 Institute of Microbiology, Department of Laboratories, Lausanne University Hospital (CHUV), Lausanne, Switzerland

3 Internal Medicine Service, Regional Hospital, Yverdon, Switzerland

4 Internal Medicine Service, Cantonal Hospital, Fribourg, Switzerland

5 Emergency Medicine Department, Lausanne University Hospital (CHUV), Lausanne, Switzerland

6 Neurology Service, Department of Clinical Neurosciences, Lausanne University Hospital (CHUV), Lausanne, Switzerland documented bacterial ( $n=18 ;$ S. pneumoniae, 11 ; N. meningitidis, 5; other, 2$)$ or viral $(n=27$ enterovirus, 21 ; VZV, 3; other, 3) etiology. CSF parameters were significantly different in bacterial vs. viral meningitis, respectively ( $p<0.001$ for all comparisons): white cell count (median 1333 vs. $143 / \mathrm{mm}^{3}$ ), proteins (median 4115 vs. $829 \mathrm{mg} / \mathrm{l}$ ), CSF/blood glucose ratio (median 0.1 vs. 0.52 ), lactate (median 13 vs. $2.3 \mathrm{mmol} / \mathrm{l})$. ROC curve analysis showed that CSF lactate had the highest accuracy for discriminating bacterial from viral meningitis, with a cutoff set at $3.5 \mathrm{mmol} / \mathrm{l}$ providing $100 \%$ sensitivity, specificity, PPV, NPV, and efficiency. CSF lactate had the best accuracy for discriminating bacterial from viral meningitis and should be included in the initial diagnostic workup of this condition.

\section{Introduction}

It is estimated that 4,100 cases of bacterial meningitis [1] and 30,000-75,000 cases of viral meningitis [2] occur annually in the United States. Bacterial and viral acute meningitis have a similar clinical presentation, characterized by the classic triad of headache, fever and neck stiffness, and by cerebrospinal fluid (CSF) pleocytosis [3, 4]. Because delayed antibiotic treatment of acute bacterial meningitis is associated with high morbidity and mortality $[5,6]$, empirical therapy is usually started pending results of microbiological cultures. CSF and blood cultures may identify a bacterial etiology after 24-72 h of incubation. An early and accurate discrimination between bacterial and viral meningitis would reduce unnecessary antibiotic use and length of hospital stay. CSF parameters, which are needed for confirmation of the acute meningitis syndrome, can be used for the etiological diagnosis, but they frequently overlap in bacterial and viral meningitis [7]. Risk scores are 
accurate, but their implementation at the bedside in the emergency department may be complex $[8,9]$.

CSF lactate is a rapid and simple test performed in the majority of routine hospital laboratories. The Infectious Diseases Society of America (IDSA) recommends to measure CSF lactate when evaluating suspected bacterial meningitis in neurosurgical patients, but not for the work-up of communityacquired bacterial meningitis, mainly due to concerns of limited specificity [10].

Studies of CSF parameters are often compromised by the lack of microbiological documentation of presumed viral cases $[11,12]$. The aim of the present study was to assess the diagnostic performance of CSF parameters, and particularly CSF lactate, for the discrimination between microbiologically documented bacterial and viral meningitis.

\section{Methods}

\section{Patients and setting}

We performed the present analysis in a prospective multicenter cohort study of adult patients hospitalized with acute meningitis. This study was designed to validate a diagnostic and therapeutic algorithm for the initial management of meningitis during the period November 2005 to October 2008 at the Lausanne University Hospital, a 1000-bed tertiary center, and in four university-affiliated hospitals of Western Switzerland [13].

The algorithm based on guidelines, evidence from the literature and local epidemiology proposed a standardized upfront clinical management for suspected bacterial meningitis. The indications for and sequential timing of lumbar puncture, empirical antibacterial therapy, cerebral CT scan, and corticosteroid therapy were established according to the severity of the clinical presentation [13].

For the present study, only patients with microbiologically documented acute meningitis fulfilling all the following criteria were included: (1) clinical presentation with at least one of the following symptoms/signs: fever, headache, neck stiffness, impaired level of consciousness, (2) CSF pleocytosis (i.e., $>4$ white blood cells $/ \mathrm{mm}^{3}$ ), and (3) microbiological documentation of the etiology (for bacterial meningitis: positive Gram stain, culture or PCR in the CSF and/or positive blood culture; for viral meningitis: positive CSF PCR or positive blood serology). Patients were excluded if they were $<16$ years old, if no LP was performed, if they had a nosocomial meningitis according to CDC criteria [14], or had a neurosurgical shunt.

The study was approved by the local Institutional Review Board [Commission cantonale d'éthique de la recherche sur l'être humain (CER-VD), Lausanne, Switzerland].

\section{Data collection}

Data on patient's demographics and baseline characteristics, clinical presentation of meningitis, blood and CSF laboratory parameters, microbiological documentation, antibacterial and corticosteroid therapy, and length of ICU and hospital stay were prospectively collected. Patient's outcome was assessed by overall in-hospital mortality and neurological disability score at discharge (Glasgow Outcome Score [15]).

Diagnostic CSF work-up included measurement of leucocyte and neutrophil count, protein (Pyrogallol red method, Randox Laboratoiries, Schwyz, Switzerland), glucose (enzymatic hexokinase test, Roche Diagnostics, Rotkreuz, Switzerland) and lactate (enzymatic lactate oxidase test, Roche Diagnostics, Rotkreuz, Switzerland). The following microbiological tests were systematically performed on the CSF in all patients presenting with acute meningitis during the study period: (1) Gram stain, (2) bacterial culture, (3) a multiplex real-time bacterial PCR targeting the four most frequent pathogens of community-acquired bacterial meningitis (Streptococcus pneumoniae, Neisseria meningitidis, Haemophilus influenzae and Listeria monocytogenes), (4) real-time viral PCR for enterovirus and herpes-simplex virus 1 and 2. The bacterial PCR was developed at our institution by combining the multiplex PCR described by Corless et al. [16] and a real-time PCR detecting Listeria monocytogenes targeting the virulence gene hly encoding the hemolysin listeriolysin [17]. Homemade viral PCRs were used [13]. Complementary diagnostic procedures were applied according to the clinical history and presentation: real-time CSF PCR for varicella-zoster virus, blood serologies for viruses (e.g., human immunodeficiency virus, tick-borne encephalitis virus) and bacteria (e.g., Borrelia burgdorferi, syphilis).

\section{Data analysis}

The diagnostic accuracy of CSF leucocyte count, neutrophil count, proteins, CSF/blood glucose ratio, and lactate for differentiating bacterial from viral meningitis was assessed by receiver operating characteristics (ROC) curves and by calculating sensitivity, specificity, positive and negative predictive values as well as efficiency after having identified the optimal cut-off (point with the shortest distance to the left upper corner of the ROC curve). Continuous variables were compared by the Mann-Whitney test and categorical variables by the Fisher's exact test. The two-tailed level of statistical significance was set at 0.05 . STATA software, version 12.1 (StataCorp, College Station, TX, USA), and GraphPad Prism, version 6.0 (GraphPad Software, Inc., San Diego, CA, USA) were used for data analysis. 


\section{Results}

\section{Patients' demographics, clinical characteristics and outcome}

Among 111 patients screened for inclusion in the prospective cohort study, 61 fulfilled the diagnostic criteria for acute meningitis. Thirteen patients in whom microbiological documentation was lacking and three in whom LP was not performed because of contraindications (coagulopathy and thrombocytopenia in two; intracranial hypertension in one) were excluded from the present analysis. Among 45 patients with microbiologically documented meningitis, 18 had bacterial meningitis (Streptococcus pneumoniae, $n=11$; Neisseria meningitidis, $n=5$; Haemophilus influenzae, $n=1$, and Streptococcus agalactiae, $n=1)$. The bacterial etiology was documented by cultures in 11 patients (blood, $n=11$; CSF, $n=10$ ), and by realtime CSF PCR in the remaining seven cases. The following etiologies were documented in 27 patients with viral meningitis: enterovirus in 21 (positive CSF PCR), varicella-zoster virus in three (positive CSF PCR), tick-borne encephalitis virus in two (positive blood serology), and herpes simplex virus type 2 in one (positive CSF PCR).

Patients' demographics and clinical characteristics at time of admission in the Emergency department are summarized in Table 1. As compared to patients with viral meningitis, patients with bacterial meningitis had a shorter time elapsed between onset of symptoms and hospital admission (median 24 vs. $42 \mathrm{~h}, p=0.03$ ), a higher rate of neck stiffness (17 out of $18,94 \%$ [95\% confidence interval (CI) $73-100]$ vs. 18 out of 27, $67 \%$ [95\% CI 46-83], $p=0.03$ ), a lower Glasgow Coma Scale (median 12 vs. 15, $p<0.001$ ), a higher white blood cell count (median 17 vs. $9.1 \mathrm{G} / 1, p<0.001$ ) and a higher median C-reactive protein (117 vs. $8.5 \mathrm{mg} / \mathrm{l}, p<0.001)$. Rates of ICU admission (14 out of $18,78 \%$ [95 \% CI 52-94] vs. 1 out of 27 , $4 \%$ [95\% CI 1-19], $p<0.001)$ and overall in-patient mortality ( 6 out of $18,33 \%$ [95\% CI $1-57$ ] vs. 0 [95\% CI $0-0$ ], $p=$ 0.002 ) were also significantly higher in patients with bacterial meningitis as compared to those with viral meningitis. A significantly higher percentage of patients with bacterial meningitis had a compromised neurological outcome, as assessed by a Glasgow Outcome Scale less than 5 (8 out of 14, 57 \% [95\% CI 29-82] vs. 2 out of $23,9 \%$ [95 \% CI 1-28], $p=0.002$ ).

\section{CSF parameters and their diagnostic accuracy}

CSF parameters in patients with bacterial and viral meningitis are compared in Fig. 1 (panel A to E). Median CSF white cell and absolute neutrophil counts, and median CSF protein and lactate concentrations were significantly higher in bacterial meningitis, while $\mathrm{CSF} / \mathrm{blood}$ glucose ratio was higher in viral meningitis. Median CSF lactate concentrations were $13 \mathrm{mmol} / 1$ in bacterial and $2.3 \mathrm{mmol} / 1$ in viral meningitis. In contrast to the other CSF parameters, no overlap for values of CSF lactate was observed between the two groups.

No correlation was found between CSF lactate concentrations and time elapsed between onset of meningitis symptoms and hospital admission or administration of the first antibiotic dose. Univariate analysis in bacterial meningitis did not show any association between CSF lactate concentrations and mortality or ICU admission. However, there was a non-significant trend toward higher lactate concentrations among bacterial meningitis patients with a Glasgow Outcome Scale lower than five (median $13.95 \mathrm{mmol} / \mathrm{l}$ ) as compared to those with a Glasgow Outcome Scale of 5 (median $9.3 \mathrm{mmol} / 1, p=0.057$ ).

The diagnostic accuracy of the CSF parameters was tested by ROC curve analysis (Fig. 2, panel A to E). The area under the curve (AUC) of CSF leucocyte count, neutrophil count,
Table 1 Demographic, clinical and cerebrospinal fluid (CSF) characteristics in patients with microbiologically documented bacterial or viral meningitis

\begin{tabular}{llll}
\hline Characteristic & $\begin{array}{l}\text { Bacterial meningitis } \\
(n=18)\end{array}$ & $\begin{array}{l}\text { Viral meningitis } \\
(n=27)\end{array}$ & $P$-value \\
\hline Median age, years (range) & $53(17-86)$ & $35(17-77)$ & 0.1 \\
Female gender (\%) & $9(50)$ & $12(44)$ & 0.5 \\
$\begin{array}{l}\text { Median time elapsed between onset of symptoms and } \\
\quad \text { hospital admission, hours (range) }\end{array}$ & $24(2-120)$ & $42(9-240)$ & 0.03 \\
Antibiotic therapy before admission (\%) & $2(11)$ & $6(22)$ & 0.4 \\
Headache (\%) & $15(83)$ & $27(100)$ & 0.06 \\
Fever (\%) & $14(78)$ & $23(85)$ & 0.7 \\
Neck stiffness (\%) & $17(95)$ & $18(67)$ & 0.03 \\
Median Glasgow Coma Scale (range) & $12(4-15)$ & $15(12-15)$ & $<0.001$ \\
Median blood white blood cell count, G/L (range) & $17(1.3-35.0)$ & $9.1(4.4-14.0)$ & $<0.001$ \\
Median blood C-reactive protein, mg/L (range) & $117(12-450)$ & $8.5(2-103)$ & $<0.001$ \\
ICU admission (\%) & $14(78)$ & $1(4)$ & $<0.001$ \\
Overall in-patient mortality (\%) & $6(33)$ & 0 & 0.002 \\
Glasgow outcome scale <5 (\%) & $8 / 14(57)$ & $2 / 23(9)$ & 0.002 \\
\hline
\end{tabular}


Fig. 1 Comparison of CSF parameters between microbiologically documented bacterial and viral meningitis. Cerebrospinal fluid (CSF) parameters in patients with microbiologically documented bacterial or viral meningitis: leucocytes (panel A), absolute neutrophil count (panel B), proteins (panel C), CSF/blood glucose ratio (panel D), lactate (panel E). Intervals of values overlapping between the two conditions are highlighted in grey
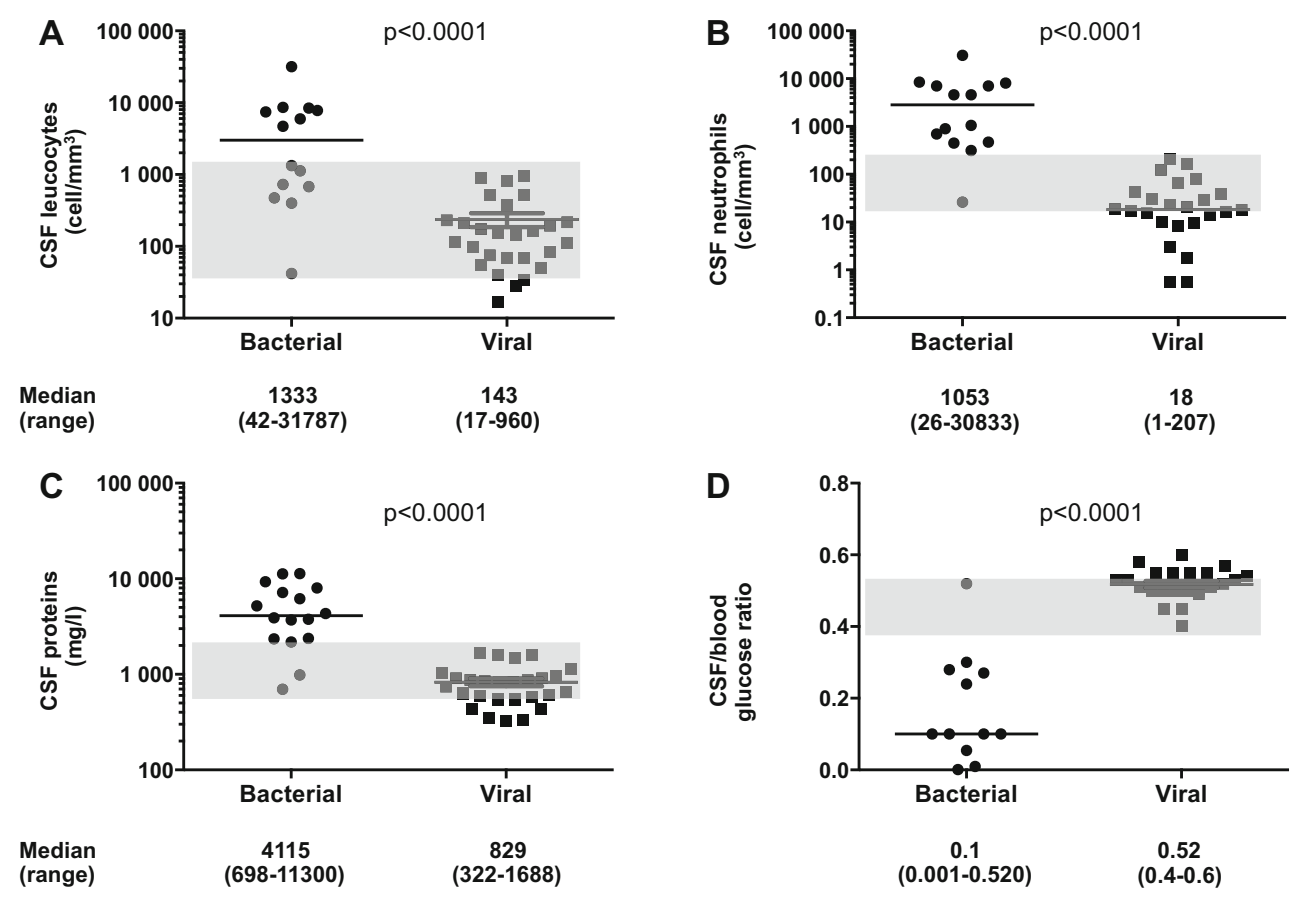

and proteins concentration was 0.89 (95\% confidence interval 0.76-1), 0.97 (95 \% CI 0.91-1), and 0.95 (95\% CI 0.88-1), respectively. The AUC of CSF/blood glucose ratio was 0.96 (95 \% CI 0.88-1), while the AUC of CSF lactate was 1 (95\% CI 1-1), with $100 \%$ sensitivity, specificity, positive predictive value (PPV), negative predictive value (NPV) and efficiency at a CSF lactate cut-off value of $3.5 \mathrm{mmol} / \mathrm{l}$ (Table 2) for distinguishing bacterial from viral meningitis. Sensitivity, specificity, PPV, NPV and efficiency at the best cut-offs of the other CSF parameters are reported in Table 2. These figures were almost identical when data from patients lacking microbiological evidence were included in the analysis.

\section{Discussion}

This analysis in a prospectively studied cohort of patients with microbiologically documented acute meningitis suggests that CSF lactate has an excellent diagnostic accuracy for

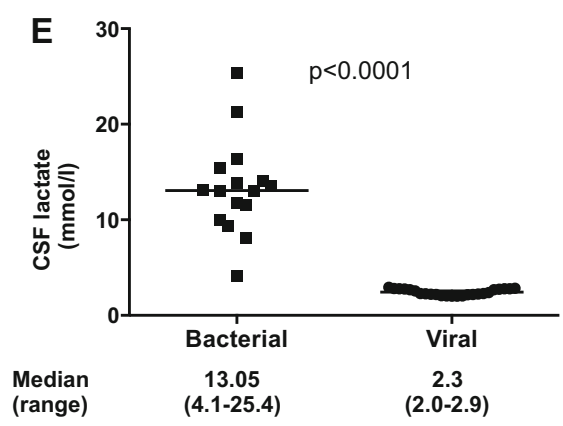

discriminating a bacterial from a viral etiology. The ROC curve analysis showed an area under the curve of 1 , and a CSF lactate cut-off of $3.5 \mathrm{mmol} / \mathrm{l}$ had $100 \%$ sensitivity, specificity, PPV, NPV, and efficiency.

The majority of routine hospital laboratories can provide measurement of CSF lactate values within a few minutes after reception of the clinical sample. By contrast to glucose, simultaneous measurements of lactate in CSF and blood are not needed, as CSF lactate levels are independent from blood levels [18]. Elevated CSF lactate in acute bacterial meningitis results from anaerobic brain metabolism related to brain edema, reduced cerebral blood flow [19], and inflammatory cytokines [20]. Guerra-Romero et al. studied central nervous system lactate production in a rabbit model of pneumococcal meningitis [21]. By measuring lactate concentrations with in situ brain microdialysis, these authors showed that sources of elevated CSF lactate were the cortex and hippocampus rather than the subarachnoid space or the 
Fig. 2 ROC curve analysis of CSF parameters. Receiver operating characteristics (ROC) curve analysis of cerebrospinal fluid (CSF) parameters for the diagnosis of bacterial meningitis: leucocytes (panel A), absolute neutrophil count (panel B), proteins (panel C), CSF/blood glucose ratio (panel D), lactate (panel E)
A

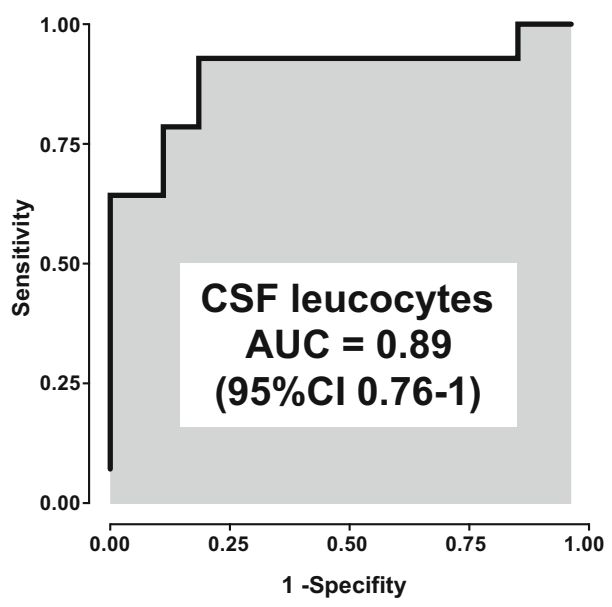

C

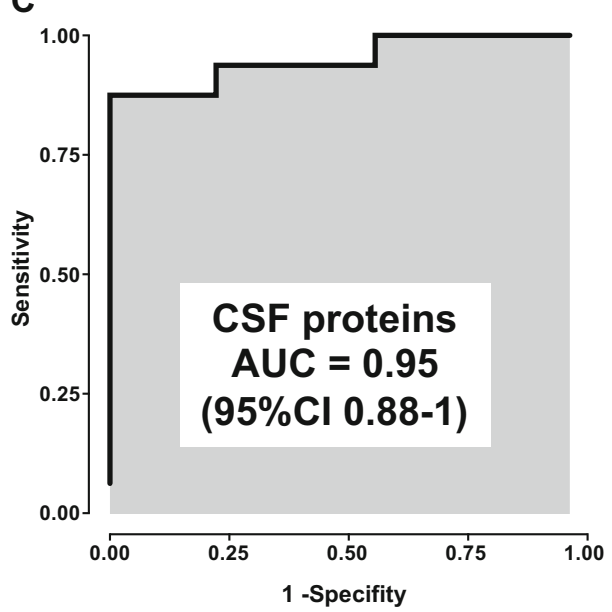

E

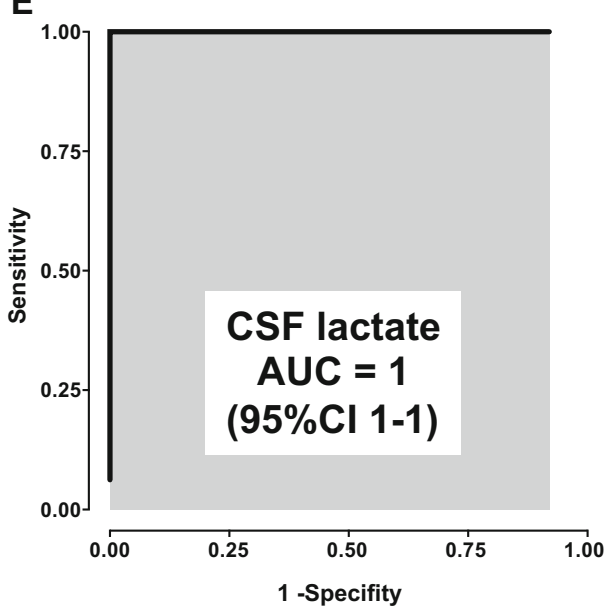

B

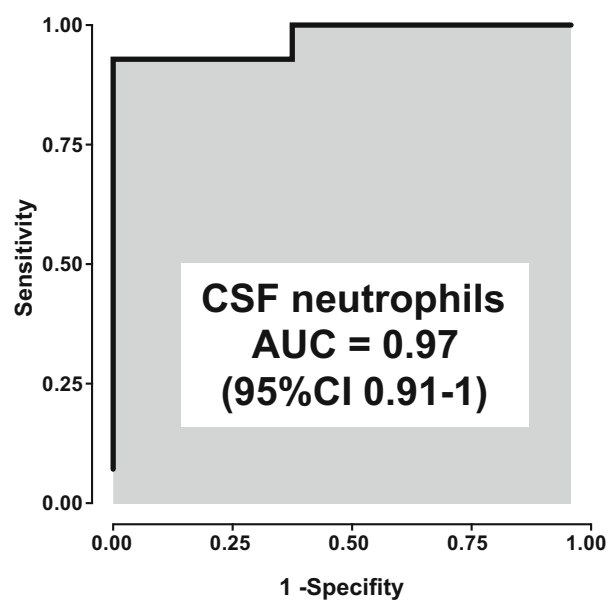

D

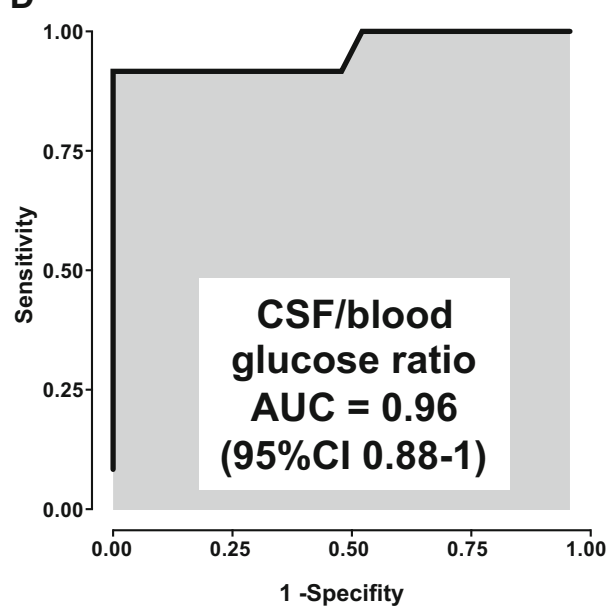

blood [21]. Elevated lactate levels are also found in other infectious or non-infectious neurological disorders such as cerebral malaria [22], seizures, ischemia, hemorrhage [23], but not in viral meningitis. Therefore, in the setting of the acute meningitis syndrome, in which non-infectious causes of elevated CSF lactate concentrations are not considered in the differential diagnosis, CSF lactate may be helpful to distinguish bacterial from viral meningitis.

The diagnostic accuracy of CSF lactate compared to that of other CSF parameters was demonstrated in postneurosurgical meningitis [24, 25]. In a retrospective study of 73 patients with suspected bacterial meningitis occurring 
Table 2 Accuracy of cerebrospinal fluid (CSF) parameters for the diagnosis of bacterial meningitis. Performance data of the best cut-off for each parameter (value indicated in parentheses in the left column) are shown

\begin{tabular}{|c|c|c|c|c|c|}
\hline Parameter & Sensitivity (\%) & Specificity (\%) & PPV (\%) & NPV $(\%)$ & Efficiency (\%) \\
\hline Leucocytes $\left(>388\right.$ cells $\left./ \mathrm{mm}^{3}\right)$ & $81(62-94)$ & $92(64-100)$ & $75(48-93)$ & $96(78-100)$ & 87 \\
\hline Neutrophils $\left(>260\right.$ cells $\left./ \mathrm{mm}^{3}\right)$ & $92(64-100)$ & $100(86-100)$ & $100(74-100)$ & $96(80-100)$ & 97 \\
\hline Proteins (>1934 mg/l) & $88(62-98)$ & $100(87-100)$ & $100(77-100)$ & $93(77-99)$ & 95 \\
\hline CSF/blood glucose ratio $(<0.35)$ & $92(62-100)$ & $100(85-100)$ & $100(71-100)$ & $96(79-100)$ & 97 \\
\hline Lactate $(>3.5 \mathrm{mmol} / \mathrm{l})$ & $100(79-100)$ & $100(86-100)$ & $100(79-100)$ & $100(86-100)$ & 100 \\
\hline
\end{tabular}

$P P V$ positive predictive value, $N P V$ negative predictive value

Ninety-five percent confidence intervals $(95 \% \mathrm{CI})$ for each performance parameter are reported in parentheses

after neurosurgery, sensitivity and specificity of CSF lactate at a cut-off of $4 \mathrm{mmol} / \mathrm{l}$ and of CSF/blood glucose ratio at a cut-off of 0.4 were $88 \%$ vs. $77 \%$ and $98 \%$ vs. $87 \%$, respectively [25]. Based on this study, guidelines of the IDSA recommend the use of CSF lactate for the diagnosis of post-neurosurgical bacterial meningitis and the initiation of empirical antibacterial therapy if CSF lactate level is $\geq 4 \mathrm{mmol} / \mathrm{l}[10]$.

In contrast, IDSA guidelines do not recommend routine CSF lactate measurement for the diagnosis of community-acquired bacterial meningitis. Due to the lack of specificity of CSF lactate, experts consider that it does not provide clinically meaningful additional information when CSF leucocytes, proteins, and glucose values are known. Nevertheless, studies in patients with acute meningitis have shown that CSF lactate is a better marker of a bacterial etiology than CSF leucocytes, neutrophils, or glucose [26-31]. A meta-analysis of 25 studies found a diagnostic odds ratio of $270(95 \% \mathrm{CI}$ 142-519) of CSF lactate at a cut-off value of $3.5 \mathrm{mmol} /$ 1 for the diagnosis of bacterial meningitis [11]. A recent study from Uganda validated CSF lactate as a useful point-of-care test for rapid diagnosis of bacterial meningitis [32]. Importantly, the lack of microbiological documentation in culture-negative meningitis of presumed viral etiology is a common limitation in the majority of the above-mentioned studies that have been performed in the pre-molecular diagnostic era. In these reports, the definition of possible viral meningitis was generally based on the combination of a clinical presentation lacking severity criteria and negative bacterial cultures $[12,26]$. However, bacterial cultures are typically negative when empirical antibacterial therapy is administered before lumbar puncture. A better indirect diagnostic criterion for viral meningitis would be a good clinical outcome in the absence of antibacterial treatment, but the large majority of patients with acute meningitis are treated empirically with high-dose antibiotics pending culture results. To avoid the bias resulting from cases of aseptic meningitis without ascertained etiology, we included only microbiologically documented cases of bacterial and viral meningitis. Furthermore, data were collected prospectively in the study cohort and CSF molecular diagnostic tests were used systematically.

The main limitation of this analysis is the relative small sample of patients. As a consequence, rarer meningitis pathogens were not represented and large confidence intervals prevented a direct comparison of the diagnostic performance between CSF parameters. The clinical efficiency and safety of using a low CSF lactate level $(<3.5 \mathrm{mmol} / \mathrm{l})$ to rule out a bacterial etiology and withhold empirical antibiotics in acute meningitis without severity criteria needs to be confirmed in larger patient populations.

In conclusion, this analysis of a prospective cohort of microbiologically documented acute meningitis showed that CSF lactate has an excellent diagnostic accuracy for differentiating bacterial from viral meningitis. The inclusion of this simple, rapid and inexpensive CSF test in the initial diagnostic workup of acute meningitis may simplify the immediate empirical management by reliably distinguishing potentially life-threatening from self-healing infections.

Acknowledgments We thank Prof. Jean-Daniel Baumgartner, Morges, Switzerland and Dr. Laurent Christin, Nyon, Switzerland for their participation in the acute meningitis cohort study.

We thank Drs. Daniel Bardy and Olivier Boulat, Laboratory of Clinical Chemistry, Department of Laboratories, Lausanne University Hospital (CHUV), for providing technical information on the studied CSF parameters.

Study funding The study was partially supported by unrestricted research grants from the Quality Control Program of the Lausanne University Hospital (Project \# 127) and the Foundation for the Advancement in Medical Microbiology and Infectious Diseases (FAMMID), Lausanne, Switzerland.

Conflict of interest The authors declare no competing financial interest in relation to the manuscript. 


\section{References}

1. Thigpen MC, Whitney CG, Messonnier NE, Zell ER, Lynfield R, Hadler JL, Harrison LH, Farley MM, Reingold A, Bennett NM, Craig AS, Schaffner W, Thomas A, Lewis MM, Scallan E, Schuchat A, Emerging Infections Programs Network (2011) Bacterial meningitis in the United States, 1998-2007. N Engl J Med 364(21):2016-2025

2. Romero JR (2014) Viral meningitis and aseptic meningitis syndrome. In: Scheld WM, Whitley RJ, Marra CM (eds) Infections of the central nervous system. Lippincott Williams \& Wilkins, Philadelphia, pp 65-83

3. van de Beek D, de Gans J, Tunkel AR, Wijdicks EF (2006) Community-acquired bacterial meningitis in adults. N Engl J Med 354(1):44-53

4. Logan SA, MacMahon E (2008) Viral meningitis. BMJ 336(7634): 36- 40

5. Aronin SI, Peduzzi P, Quagliarello VJ (1998) Community-acquired bacterial meningitis: risk stratification for adverse clinical outcome and effect of antibiotic timing. Ann Intern Med 129(11):862-869

6. Auburtin M, Wolff M, Charpentier J, Varon E, Le Tulzo Y, Girault C, Mohammedi I, Renard B, Mourvillier B, Bruneel F, Ricard JD, Timsit JF (2006) Detrimental role of delayed antibiotic administration and penicillin-nonsusceptible strains in adult intensive care unit patients with pneumococcal meningitis: the PNEUMOREA prospective multicenter study. Crit Care Med 34(11):2758-2765

7. Brouwer MC, Thwaites GE, Tunkel AR, van de Beek D (2012) Dilemmas in the diagnosis of acute community-acquired bacterial meningitis. Lancet 380(9854):1684-1692

8. Nigrovic LE, Kuppermann N, Macias CG, Cannavino CR, MoroSutherland DM, Schremmer RD, Schwab SH, Agrawal D, Mansour KM, Bennett JE, Katsogridakis YL, Mohseni MM, Bulloch B, Steele DW, Kaplan RL, Herman MI, Bandyopadhyay S, Dayan P, Truong UT, Wang VJ, Bonsu BK, Chapman JL, Kanegaye JT, Malley R, Pediatric Emergency Medicine Collaborative Research Committee of the American Academy of Pediatrics (2007) Clinical prediction rule for identifying children with cerebrospinal fluid pleocytosis at very low risk of bacterial meningitis. JAMA 297(1):52-60

9. Spanos A, Harrell FE Jr, Durack DT (1989) Differential diagnosis of acute meningitis. An analysis of the predictive value of initial observations. JAMA 262(19):2700-2707

10. Tunkel AR, Hartman BJ, Kaplan SL, Kaufman BA, Roos KL, Scheld WM, Whitley RJ (2004) Practice guidelines for the management of bacterial meningitis. Clin Infect Dis 39(9):1267-1284

11. Huy NT, Thao NT, Diep DT, Kikuchi M, Zamora J, Hirayama K (2010) Cerebrospinal fluid lactate concentration to distinguish bacterial from aseptic meningitis: a systemic review and meta-analysis. Crit Care 14(6):R240

12. Prasad K, Sahu JK (2011) Cerebrospinal fluid lactate: is it a reliable and valid marker to distinguish between acute bacterial meningitis and aseptic meningitis? Crit Care 15(1):104

13. Giulieri SG, Chapuis-Taillard C, Manuel O, Hugli O, Pinget C, Wasserfallen JB, Sahli R, Jaton K, Marchetti O, Meylan P (2015) Rapid detection of enterovirus in cerebrospinal fluid by a fullyautomated PCR assay is associated with improved management of aseptic meningitis in adult patients. J Clin Virol 62:58-62

14. Horan TC, Andrus M, Dudeck MA (2008) CDC/NHSN surveillance definition of health care-associated infection and criteria for specific types of infections in the acute care setting. Am J Infect Control 36(5):309-332
15. de Gans J, van de Beek D, European Dexamethasone in Adulthood Bacterial Meningitis Study Investigators (2002) Dexamethasone in adults with bacterial meningitis. N Engl J Med 347(20):1549-1556

16. Corless CE, Guiver M, Borrow R, Edwards-Jones V, Fox AJ, Kaczmarski EB (2001) Simultaneous detection of Neisseria meningitidis, Haemophilus influenzae, and streptococcus pneumoniae in suspected cases of meningitis and septicemia using real-time PCR. J Clin Microbiol 39(4):1553-1558

17. Rodriguez-Lazaro D, Hernandez M, Scortti M, Esteve T, VazquezBoland JA, Pla M (2004) Quantitative detection of Listeria monocytogenes and Listeria innocua by real-time PCR: assessment of hly, iap, and lin02483 targets and AmpliFluor technology. Appl Environ Microbiol 70(3):1366-1377

18. Posner JB, Plum F (1967) Independence of blood and cerebrospinal fluid lactate. Arch Neurol 16(5):492-496

19. Meli DN, Christen S, Leib SL, Tauber MG (2002) Current concepts in the pathogenesis of meningitis caused by Streptococcus pneumoniae. Curr Opin Infect Dis 15(3):253-257

20. Tureen J (1995) Effect of recombinant human tumor necrosis factor-alpha on cerebral oxygen uptake, cerebrospinal fluid lactate, and cerebral blood flow in the rabbit: role of nitric oxide. J Clin Invest 95(3):1086-1091

21. Guerra-Romero L, Tauber MG, Fournier MA, Tureen JH (1992) Lactate and glucose concentrations in brain interstitial fluid, cerebrospinal fluid, and serum during experimental pneumococcal meningitis. J Infect Dis 166(3):546-550

22. White NJ, Warrell DA, Looareesuwan S, Chanthavanich P, Phillips RE, Pongpaew P (1985) Pathophysiological and prognostic significance of cerebrospinal-fluid lactate in cerebral malaria. Lancet 1(8432):776-778

23. Cunha BA (2013) The clinical and laboratory diagnosis of acute meningitis and acute encephalitis. Expert Opin Med Diagn 7(4): 343-364

24. Maskin LP, Capparelli F, Mora A, Hlavnicka A, Orellana N, Díaz MF, Wainsztein N, Del Castillo M. Cerebrospinal fluid lactate in post-neurosurgical bacterial meningitis diagnosis. Clin Neurol Neurosurg 115(9):1820-1825

25. Leib SL, Boscacci R, Gratzl O, Zimmerli W (1999) Predictive value of cerebrospinal fluid (CSF) lactate level versus CSF/blood glucose ratio for the diagnosis of bacterial meningitis following neurosurgery. Clin Infect Dis 29(1):69-74

26. Genton B, Berger JP (1990) Cerebrospinal fluid lactate in 78 cases of adult meningitis. Intensive Care Med 16(3):196-200

27. Sakushima K, Hayashino Y, Kawaguchi T, Jackson JL, Fukuhara S (2011) Diagnostic accuracy of cerebrospinal fluid lactate for differentiating bacterial meningitis from aseptic meningitis: a meta-analysis. J Infect 62(4):255-262

28. Ponka A, Ojala K, Teppo AM, Weber TH (1983) The differential diagnosis of bacterial and aseptic meningitis using cerebrospinal fluid laboratory tests. Infection 11(3):129-131

29. Mandal BK, Dunbar EM, Hooper J, Parker L (1983) How useful is cerebrospinal fluid lactate estimation in differential diagnosis of meningitis? J Infect 6(3):231-237

30. Briem H (1983) Comparison between cerebrospinal fluid concentrations of glucose, total protein, chloride, lactate, and total amino acids for the differential diagnosis of patients with meningitis. Scand J Infect Dis 15(3):277-284

31. Eross J, Silink M, Dorman D (1981) Cerebrospinal fluid lactic acidosis in bacterial meningitis. Arch Dis Child 56(9):692-698

32. Majwala A, Burke R, Patterson W, Pinkerton R, Muzoora C, Wilson LA, Moore CC (2013) Handheld point-of-care cerebrospinal fluid lactate testing predicts bacterial meningitis in Uganda. Am J Trop Med Hyg 88(1):127-131 